
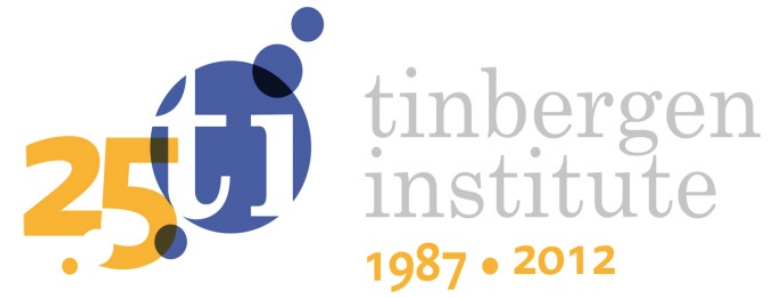

\title{
Collective versus Decentralized Wage Bargaining and the Efficient Allocation of Resources
}

Xiaoming Cai

Pieter A. Gautier

Makoto Watanabe 
Tinbergen Institute is the graduate school and research institute in economics of Erasmus University Rotterdam, the University of Amsterdam and VU University Amsterdam.

More TI discussion papers can be downloaded at http://www.tinbergen.nl

Tinbergen Institute has two locations:

Tinbergen Institute Amsterdam

Gustav Mahlerplein 117

1082 MS Amsterdam

The Netherlands

Tel.: +31(0)205251600

Tinbergen Institute Rotterdam

Burg. Oudlaan 50

3062 PA Rotterdam

The Netherlands

Tel.: +31(0)10 4088900

Fax: $+31(0) 104089031$

Duisenberg school of finance is a collaboration of the Dutch financial sector and universities, with the ambition to support innovative research and offer top quality academic education in core areas of finance.

DSF research papers can be downloaded at: http://www.dsf.nl/

Duisenberg school of finance

Gustav Mahlerplein 117

1082 MS Amsterdam

The Netherlands

Tel.: +31(0)20 5258579 


\title{
Collective versus decentralized wage bargaining and the efficient allocation of resources
}

\author{
Xiaoming Cai*, Pieter A. Gautierł, and Makoto Watanabe ${ }^{\ddagger}$
}

September 2012

\begin{abstract}
An advantage of collective wage agreement is that search and business-stealing externalities can be internalized. A disadvantage is that it takes more time before an optimal allocation is reached because more productive firms (for a particular worker type) can no longer signal this by posting higher wages. Specifically, we consider a search model with two sided heterogeneity and on-the-job search. We compare the most favorable case of a collective wage agreement (i.e. the wage that a planner would choose under the constraint that all firms in a sector-occupation cell must offer the same wage) with the case without collective wage agreement. We find that collective wage agreements are never desirable if firms can commit ex ante to a wage and only desirable if firms cannot commit and the relative efficiency of on the job search to off- the job search is less than $20 \%$. This result is hardly sensitive to the bargaining power of workers. Empirically we find both for the Netherlands and the US that this value is closer to $50 \%$.
\end{abstract}

*Vrije Universiteit Amsterdam, Tinbergen Institute, xmingcai@gmail.com

$\dagger$ VU Amsterdam, Tinbergen Institute, Address: Department of Economics, VU Amsterdam, De Boelelaan 1105, NL-1081 HV Amsterdam, The Netherlands, p.a.gautier@vu.nl

‡VU Amsterdam, Tinbergen Institute, makoto.wtnb@gmail.com 


\section{Introduction}

Under collective bargaining agreements (CBA), wages are determined at the industry level rather than at the individual level. An advantage of collective wage bargaining is that potential externalities can be internalized while a disadvantage is that the signalling role of wages is eliminated which leads to a sub optimal allocation of workers over jobs. To study this trade-off we need a model that allows for two sided heterogeneity and search frictions. Heterogeneity is important because we are interested in the allocation of workers. Search frictions are important because it takes time for workers to find the production units where they are needed most and we will see that wages play a potentially important signalling role.

This paper uses a circular model similar to Marimon and Zilibotti (1999) and Gautier, Teulings and van Vuuren (2010). The idea is that worker $(s)$ and job types $(c)$ are located on a circle and productivity is decreasing in the distance, $x$, between $s$ and $c .{ }^{1}$ In the centralized-wage setting case, all firm types, $c$, must offer the same wage while in the decentralized case, firm types $c$ are allowed to post different wages to different worker types, s. We distinguish between contracts where firms can and where they cannot ex ante commit to a wage schedule. One may argue that it is easy to write wage contracts but contracts conditional on $x$ are difficult to verify in court. Moreover, if renegotiation is possible, ex ante commitment also becomes meaningless. When firms can commit ex ante, the decentralized mechanism only becomes more favorable relative to the CBA case.

Gautier et al. (2010) show for the no-commitment case that firms engage in excessive vacancy creation due to a business-stealing effect. The idea is that firms do not internalize the output loss of firms they poach a worker from, in particular, they do not care whether they destroy relatively good or bad matches. Although each worker's transition is efficient, the expected marginal increase in aggraded output is too low to justify the entry cost. In the CBA case, the wage can be set at a level that generates the efficient level of entry. However, if all firms in a sector pay the same wage, workers do not know which firms need

\footnotetext{
${ }^{1}$ The results of Gautier, Teulings and Van Vuuren (2005) show that without on-the-job search, the circular model has the same characteristics as a Taylor expansion of the hierarchical model.
} 
their services most and once they have a job they stop searching. We are interested in the trade-off between efficient entry and efficient allocation and which wage mechanism is most desirable from a social welfare point of view.

The desirability of CBA mainly depends on the efficiency of on-the-job search relative to off the job search $(\psi)$. If employed job seekers receive more than $20 \%$ of the number of offers as the unemployed workers (for the commitment case it is more than 10\%), the cost of CBA exceed the benefits. The reason for this is that the more efficient on-the-job search is, the faster workers flow to the jobs where they are needed most and the more costly it is if CBA prevents firms within an industry to signal with wages that they need a particular worker type. We then use the ratio of job-to-job- to-unemployment-employment flows to estimate $\psi$ to be 0.45 for the Netherlands and around $0.5-0.75$ for the US. In the range of empirically feasible values of $\psi, \mathrm{CBA}$ is not desirable. We also simulate the model for general bargaining power. CBA is less desirable if the worker 's bargaining position increases until the bargaining power is around 0.4. For $\beta=0$, CBA is less inefficient than for higher $\beta$ 's (for the empirical values of $\psi$ ).

This paper is related to a number of other papers that study the effect of centralized bargaining in frictional labor markets. Pissarides (1986) asks whether the standard search externalities will be internalized by a union. He finds that this is the case only if the union's policy is chosen by unemployed persons. If employed persons can influence the union's policy, unemployment and wages will be too high. Other models that have frictions and centralized bargaining include Delacroix (2006) and Bauer and Lingens (2011). None of those models look at the trade-off between an efficient allocation and internalizing externalities as we do. Finally, Krusell and Rudanko (2012) focus on union wage setting rather than CBA's. They assume that in the long run unions internalize all externalities but in the short run, they raise current wages above the efficient level, in order to appropriate surpluses from firms with existing matches. This implies that the union wage policy is time-inconsistent. They allow wage for wage dispersion within industries and occupations whereas in our CBA's the wage is fixed at the job level.

The paper is organized as follows. Section 2 starts with the assumptions, derives 
the equilibrium conditions, and characterizes the equilibrium. Section 3 conducts welfare analysis and Section 4 concludes.

\section{The model}

\subsection{Assumptions}

Point of departure is Marimon and Zilibotti (1999) and Gautier, Teulings and van Vuuren (2010). Worker $(s)$ and job types $(c)$ are locations on a circle with circumference 1 . The production technology has constant-returns-to scale so it is easiest to think of firms as consisting of one worker. A matched firm-worker pair produces $Y$ which depends on the "spherical distance" between $s$ and $c: x(s, c)=\min \{|s-c|, 1-|s-c|\}$. Note $0 \leq x(s, c) \leq$ 1/2. Specifically, $Y(s, c)=Y(x)$. Since we interpret $x$ as an indicator of mismatch between works and jobs, $Y(x)$ has a maximum at 0 , and the value of the maximum is normalized to unity: $Y(0)=1$. Also we assume that $Y(x)$ is twice differentiable and strictly quasi concave. Since we treat the circular mismatch model as a simplified version of a more general matching model, for example Shimer and Smith (2000), the derivative of $Y(x)$ at 0 should be 0 . A simple example of the more general matching model would be $Y(s, c)=s c=\frac{1}{4}(s+c)^{2}-\frac{1}{4}(s-c)^{2}$. The first term could be thought as the average productivity and the second term as indicator of mismatch. A simple functional forms that meets those criteria is,

$$
Y(x)=1-\frac{1}{2} \gamma x^{2}
$$

As Gautier et al. (2010) argue, this functional form can be thought of as second-order Taylor series expansion of a more general (differentiable) production function. Low values of $\gamma$ imply that a precise match is not very important, in the extreme when $\gamma \rightarrow 0$, the model reduces to a standard Diamond-Mortensen-Pissarides type of matching model with identical workers and firms.

Assume that labor supply per $s$-type is uniformly distributed over the the circle and that total labor supply in period $t$ equals $L(t)$. We also assume that vacancies are uniformly distributed over the circumference of the circle: $v(c)=v$, where $v(c)$ is the number 
of vacancies per unit of $c$ (one can show that this is an equilibrium). One can show that this is an equilibrium. The value of non-market time is B. Labor demand is determined by free entry of vacancies for all $c$-types. The flow cost of maintaining a vacancy is equal to $K$ per period.

We assume that $\rho$ equals the population growth rate (golden growth) and that all new workers start out as unemployed. The implications of this assumption are the same as under assuming that the discount rate $\rho$ is much smaller than the job-finding and separation rate, $\rho \ll \delta, \lambda$. This is a common assumption in the wage-posting literature (see for example, Burdett and Mortensen,1998).

Next, we discuss the job search technology. Let $m$ be the total number of contacts between job seekers and vacancies per unit of labor supply, $u$ the unemployment rate, and $v$ is total number of vacancies per unit of labor supply. Assume that the contact technology is quadratic. Then,

$$
m=\lambda[u+\psi(1-u)]
$$

The parameter $\psi, 0 \leq \psi \leq 1$, measures the relative efficiency of on-the-job search versus search while unemployed. Marimon and Zilibotti (1999) consider the case, $\psi=0$ which is related to the stochastic matching model of Pissarides (2000). If off- and on-the-job search are equally efficient, $\psi=1$ the model is relatively simple and analytical results can be obtained. For general $\psi=0$, we depend on numerical simulations. The overall efficiency of the matching process is captured by $\lambda$. The Walrasian equilibrium is obtained for $\lambda \rightarrow \infty$. Finally, we assume that matches between workers and jobs are destroyed at an exogenous rate $\delta>0$.

We focus on two wage-setting schemes. First, in the centralized case, all firms of the same type pay the same wage and to make this case as favorable as possible, we set this wage optimally from a social point of view. In the decentralized case, we assume first that wages are determined by bilaterally efficient bargaining between the worker and the firm where firms cannot commit on future wage payments, see Coles (2001), Shimer (2006), Gautier et al. (2011) and Coles and Mortensen (2011). So, firms pay only "no-quit" 
premia but no "hiring" premia. Second, we assume that firms can commit on a future wage policy that is contingent on $x$ in the current job. So, firms pay both "no-quit" premia and "hiring" premia.

\subsection{Job dynamics and asset values}

Both under commitment and no commitment, workers will move in the direction of their optimal job type and the laws of motion are the same. Therefore, we can first solve for the worker flows and the asset values of vacancies, employment and unemployment for a given wage setting rule. Under both wage mechanisms, wages are decreasing in $x$, as is proved in Gautier et al. (2010). This allows us to write the wage schedule as a function of $x, W(x)$ rather than $W(s, c)$. Denote by $G(x)$ the fraction of workers employed at jobs at smaller distance from their optimal job than $x .^{2}$ Let $\bar{x}$ be the reservation distance from their optimal job for an unemployed workers. Job located at a further distance are declined. This implies that $G(\bar{x})=1$. At the golden-growth path, unemployment and employment must grow at the same rate. The inflow into the class of employed workers at distance $x$ or less from their favorite job minus the outflow from this class must therefore equal the population growth rate:

$$
2 \lambda v x\{u+\psi(1-u)[1-G(x)]\}-\delta(1-u) G(x)=\rho(1-u) G(x) .
$$

The first term on the left-hand side is the number of people that finds a job at a distance less than $x$ from the optimal job. The previous state was either from unemployment (the first term in parentheses), or employed at a job located at a larger distance (the second term in parentheses). The number of better jobs is given by $2 v x$, since the worker accept jobs both to the left and to the right of the optimal job type $s=c$ (or, equivalently, $x=0)$. The second term in brackets is weighted by the factor $\psi$, reflecting the efficiency of on-the-job search relative to search while unemployed. The final term on the left-hand side is the outflow of workers from the class of matches with mismatch indicator of $x$ or less: $\delta G(x)$. The right-hand side reflects that at the balanced growth path, employment

\footnotetext{
${ }^{2}$ We assume that at a tie, the worker moves with a positive probability; see also Shimer (2006).
} 
grows at a rate $\rho$ at all levels including the class of workers with a mismatch indicator smaller than $x, G(x)$. Mobility within this class is irrelevant because the old and the new match cancel. Steady-state unemployment can be derived from evaluating (1) at $\bar{x}$.

$$
\begin{aligned}
u & =\frac{1}{1+\kappa v \bar{x}}, \\
\text { where } \kappa & \equiv \frac{2 \lambda}{\rho+\delta} .
\end{aligned}
$$

Note that on the balanced-growth path, $u$ and $G(x)$ are constant. Substitution of (2) for $u$ in the balanced-growth condition (1) yields

$$
G(x)=1-\frac{\bar{x}-x}{(1+\psi \kappa v x) \bar{x}} .
$$

with the corresponding density

$$
g(x)=\frac{1+\psi \kappa v \bar{x}}{\bar{x}(1+\psi \kappa v x)^{2}} .
$$

Free entry implies that the option value of a vacancy of type $c$ must be equal to $K$. Define $\mathrm{E}_{G} Y \equiv \int_{0}^{\bar{x}} g(x) Y(x) d x$ and $\mathrm{E}_{G} W \equiv \int_{0}^{\bar{x}} g(x) W(x) d x$, then,

$$
\begin{aligned}
K & =2 \lambda \int_{0}^{\bar{x}}\{u+\psi(1-u)[1-G(x)]\} \frac{Y(x)-W(x)}{\rho+\delta+2 \psi \lambda v x} d x \\
& =\frac{1-u}{v}\left(\mathrm{E}_{G} Y-\mathrm{E}_{G} W\right) .
\end{aligned}
$$

where in the CBA case, $\psi=0$ and $W(x)=W^{c}$. Starting off with the first equality, the first factor in the integrand is the effective fraction of individuals $u+\psi(1-u)[1-G(x)]$ willing to accept a type $x$ match. It equals the number of unemployed, $u$ plus the number of workers employed in jobs with a greater mismatch indicator than $x,(1-u)[1-G(x)]$; the latter number is scaled down with $\psi$ to account for a lower effectiveness of on-the-job search. The second factor is the value of a filled vacancy. Just as in the wage equation, we discount current revenue $Y(x)-W(x)$ by the discount rate $\rho$ plus the separation rate $\delta$ plus the quit rate $2 \psi \lambda v x$. The second line follows from substitution of the relations for employment and unemployment. Multiplying (6) by $v$ gives a simple interpretation of this zero-profit condition: at any point in time, the cost of vacancies, $v K$, is equal to the employment rate $(1-u)$ times the expected profit in a filled vacancy, $\left(\mathrm{E}_{G} Y-\mathrm{E}_{G} W\right)$. 


\subsection{Decentralized wage setting with and without commitment}

Let $W(x)$ be the wage for a job with mismatch indicator $x$ and let $V^{U}$ be the asset value of unemployment. For the two wage mechanisms that we consider, we can write the asset value for a worker holding a job at distance $x$ from his optimal job type, $V^{E}(x)$ as

$$
\rho V^{E}(x)=W(x)+2 \psi \lambda v \int_{0}^{x}\left[V^{E}(z)-V^{E}(x)\right] d z-\delta\left[V^{E}(x)-V^{U}\right] .
$$

The asset value for an unemployed job seeker satisfies the Bellman equation:

$$
\rho V^{U}=B+2 \lambda v \int_{0}^{\bar{x}}\left[V^{E}(x)-V^{U}\right] d x .
$$

For the marginal job, $x=\bar{x}$, the asset value of the job is equal to the asset value of unemployment: $V^{E}(\bar{x})=V^{U}$. Evaluating (7) at $\bar{x}$ and using the definition of $g$ in (5) gives

$$
\rho V^{E}(\bar{x})=\rho V^{U}=\frac{W(\bar{x})+\psi \kappa v \bar{x} \mathrm{E}_{G} W}{1+\psi \kappa v \bar{x}}=\frac{u W(\bar{x})+\psi(1-u) \mathrm{E}_{G} W}{u+\psi(1-u)} .
$$

The asset value in the marginal job is a weighted average of the wage in the current job $W(\bar{x})$ (the reservation wage) and the expected wage in the next job, $\mathrm{E}_{G} W$. Finally, we can write the value of unemployment as a weighted average of the value of leisure $B$ and the expected wage ${ }^{3}$,

$$
\rho V^{U}=\frac{B+\kappa v \bar{x} \mathrm{E}_{G} W}{1+\kappa v \bar{x}}=u B+(1-u) \mathrm{E}_{G} W,
$$

where the final step uses (2).

Equations (2), (5), (6), (9), and (10) determine $u, v, \rho V^{U}, \bar{x}$ and $G(x)$. The wage function $W(x)$ (which we need to derive $\mathrm{E}_{G} W$ ) for the non centralized cases for general bargaining power of worker $\beta$ is derived in Gautier et al. (2011). Let $W^{n c}(x)$ be the wage in the no-commitment case and $W^{c}$ in the commitment case. For the special case that

\footnotetext{
${ }^{3}$ Use the fact that the right-hand side of (7) and (9) are equal allows us to obtain an expression for $\int_{0}^{\bar{x}}\left[V^{E}(x)-V^{U}\right] d x$. Substitution of this expression into (8) allows us to write $\rho V^{U}$ as a function of $W(\bar{x})$, which can be substituted out by solving $(9)$ for $W(\bar{x})$.
} 
$\beta=0$, both are implicitly determined by the following differential equations in $x$.

$$
\begin{aligned}
W_{x}^{n c}(x) & =-\frac{\psi \kappa v\left[Y(x)-W^{n c}(x)\right]}{1+\psi \kappa v x} \\
W_{x}^{c}(x) & =-2 \frac{\psi \kappa v\left[Y(x)-W^{c}(x)\right]}{1+\psi \kappa v x}
\end{aligned}
$$

where the initial condition is given by (13). The factor 2 in (12) comes from the fact that in equilibrium the no-quit premium is equal to the hiring premium (the latter is absent under no commitment).

$$
W^{i}(\bar{x})=Y(\bar{x})=1-\frac{1}{2} \gamma \bar{x}^{2}
$$

where $i=c$ or $n c$.

Definition 1 The equilibrium consists of the set $\left\{u, v, \bar{x}, W^{i}(\bar{x}), W^{i}(x), G(x)\right\}$ satisfying the equations (2), (4), (6), (10), (11) or (12), and (13).

The solution of the differential equation (12) for the commitment case is,

$$
W^{c}(x)=1-\gamma\left[\left(\frac{1+\psi x}{\psi}\right)^{2} \log \left(\frac{1+\psi \bar{x}}{1+\psi x}\right)-\frac{\bar{x}}{\psi} \frac{(1+\psi x)^{2}}{1+\psi \bar{x}}+\frac{x}{\psi}+\frac{3}{2} x^{2}\right]
$$

while for the commitment case it is,

$$
W^{n c}(x)=1-\gamma\left[\frac{1+\psi x}{\psi^{2}} \ln \left(\frac{1+\psi x}{1+\psi \bar{x}}\right)-\frac{x-\bar{x}}{\psi}-\frac{1}{2} x(x-2 \bar{x})\right] .
$$

See Gautier et al. (2011) for a proof.

\subsection{Centralized wage setting (CBA)}

In this subsection, we derive the equilibrium if all firms are obliged to pay a wage that arises through collective wage bargaining, $W^{c b}$, then workers have no incentives to continue searching on the job and $\bar{x}$ follows from the fact that at the marginal job, the worker gets all the output, $Y(\bar{x})=1-\frac{1}{2} \gamma \bar{x}^{2}=W^{c b}$ or

$$
\bar{x}=\sqrt{\frac{2\left(1-W^{c}\right)}{\gamma}}
$$


The value of employment is given by,

$$
\rho V^{E}\left(W^{c b}\right)=W^{c b}-\delta\left[V^{E}\left(W^{c b}\right)-V^{U}\right]
$$

The asset value for an unemployed job seeker satisfies the Bellman equation:

$$
\rho V^{U}=B+2 \lambda \bar{x} v\left[V^{E}\left(W^{c b}\right)-V^{U}\right]
$$

where $2 \lambda \bar{x} v$ is the set of acceptable jobs.

By using the free entry condition, we can find the values of $K$ for which an equilibrium exists with a positive vacancy stock.

$$
v=\frac{1-u}{K}\left(\mathrm{E}_{\tilde{G}} Y-W^{c b}\right)
$$

Note that because of collective wage bargaining, there is no on-the-job search in this environment, and consequently there are no job-to-job movements. So the new distribution for mismatch $x$ is,

$$
\tilde{G}(x)=1-\frac{x}{\bar{x}}
$$

This is a special case of Equation (4) with the on-the-job search parameter $\psi$ set equal to 0 .

Proposition 2 Given a collective wage $W^{c b}$, the equilibrium with $C B A$ is characterized by the following first order condition,

$$
\frac{K}{\kappa u}=\frac{2}{3} \sqrt{\frac{2}{\gamma}}\left(1-W^{c b}\right)^{\frac{3}{2}},
$$

where $\kappa$ is given by Equation 3.

Proof. Combine Equations (2), (14), and (??)

From the above equation, it can be easily seen that the unemployment rate $u$ is increasing in $W^{c b}$. A higher collective wage will lead to a higher unemployment rate. 


\section{$2.5 \quad$ Efficiency}

Define net output $\Omega$ as,

$$
\begin{aligned}
\Omega & \equiv(1-u) \mathrm{E}_{G} Y+u B-v K \\
& =(1-u) \mathrm{E}_{G} Y+u B-\frac{(1-u) v}{v}\left(\mathrm{E}_{G} Y-\mathrm{E}_{G} W\right) \\
& =u B+(1-u) \mathrm{E}_{G} W .
\end{aligned}
$$

Note the equality in the second line holds in both the decentralized wage bargaining and the collective wage bargaining. The first term is actual output of the employed workers, the second term captures the value of leisure of the unemployed job seekers, and the third term is the cost of keeping vacancies open. Under free entry the difference between output and wages goes into vacancy creation and the final step tells us that net output is equal to the value of unemployment.

So far we haven't specified any rule for wage determination in the CBA case. To make comparisons, we assume that the wage in the CBA case is set to maximize the net output. By combing Equations (17) and (18), the wage that maximizes net output satisfies,

$$
K\left(1-\frac{3}{2} B\right)=\kappa \sqrt{\frac{2}{\gamma}}\left(1-W^{c b}\right)^{\frac{3}{2}}-\frac{1}{2} K W^{c b} .
$$

In the next section, we will solve the model numerically for general $\beta$ and $\psi$ and derive the conditions under which CBA is more desirable than decentralized wage setting.

\section{$3 \quad$ Numerical simulations}

In this section we first give a simple description of the numerical procedure that we follow to solve the models, and then we present our main results.

\subsection{When does decentralized wage setting performs better than CBA}

The main challenge of numerically solving the decentralized wage bargaining case without commitment is that for general $\beta$, we don't have an analytical solution for the wage 
Table 1: Parameter Values

\begin{tabular}{ccl|ccl}
\hline \hline$\lambda$ & 1 & matching technology parameter & $\rho$ & 0.01 & discount rate \\
$K$ & 0.1 & vacancy cost & $B$ & 0.6 & leisure value \\
$\gamma$ & 12 & production function parameter & $\delta$ & 0.03 & job separation rate \\
\hline
\end{tabular}

equation. In Appendix A we present the differential equation. In order to numerically solve it we use a Chebyshev polynomial to approximate the wage equation. Given $\bar{x}$ and $v$, we can find a polynomial minimizing the difference between the left and the right hand side of (20) at the Chebyshev nodes. Then the program will search for $\bar{x}$ and $v$ satisfying the equilibrium conditions (6), (9), and (10).

We list the parameter values used in the model in Table 1. In the table, we left unspecified the on-the-job search efficiency parameter $\psi$ and the bargaining power parameter $\beta$ in the no-commitment wage case. The values of discount rate $\rho$, leisure value $B$, and the job separation rate $\delta$ all have empirical counterparts, and are based on previous studies, for example Shimer (2005). The values of the scaling parameter $\lambda$ in the matching function, $\gamma$ in the production function, and vacancy cost $K$ are selected to match the reasonable unemployment rate and the empirical variance of the matching quality $x$. The latter criterion is also used by Gautier and Teulings (2011).

As proved in Gautier et al. (2010) when $\psi=1$, the commitment case can achieve the social optimal outcome. However, even when $\psi<1$, for a large range of $\psi$ values, the social optimum and the wage with commitment case are almost indistinguishable. The reason is that as long as $\psi$ is sufficiently large, the workers do not lose much option value by accepting a job offer. Furthermore, compared to the non-commitment case, there is more competition for workers and therefore, vacancy creation is lower or absent and this improves social efficiency.

If we compare welfare for all three cases, Figure 1 shows that when $\psi$ is very small $(<0.12)$, the optimal centralized wage performs better than the commitment case. This threshold is higher for the no-commitment case. I.e. for $\psi<0.30$, CBA outperforms 


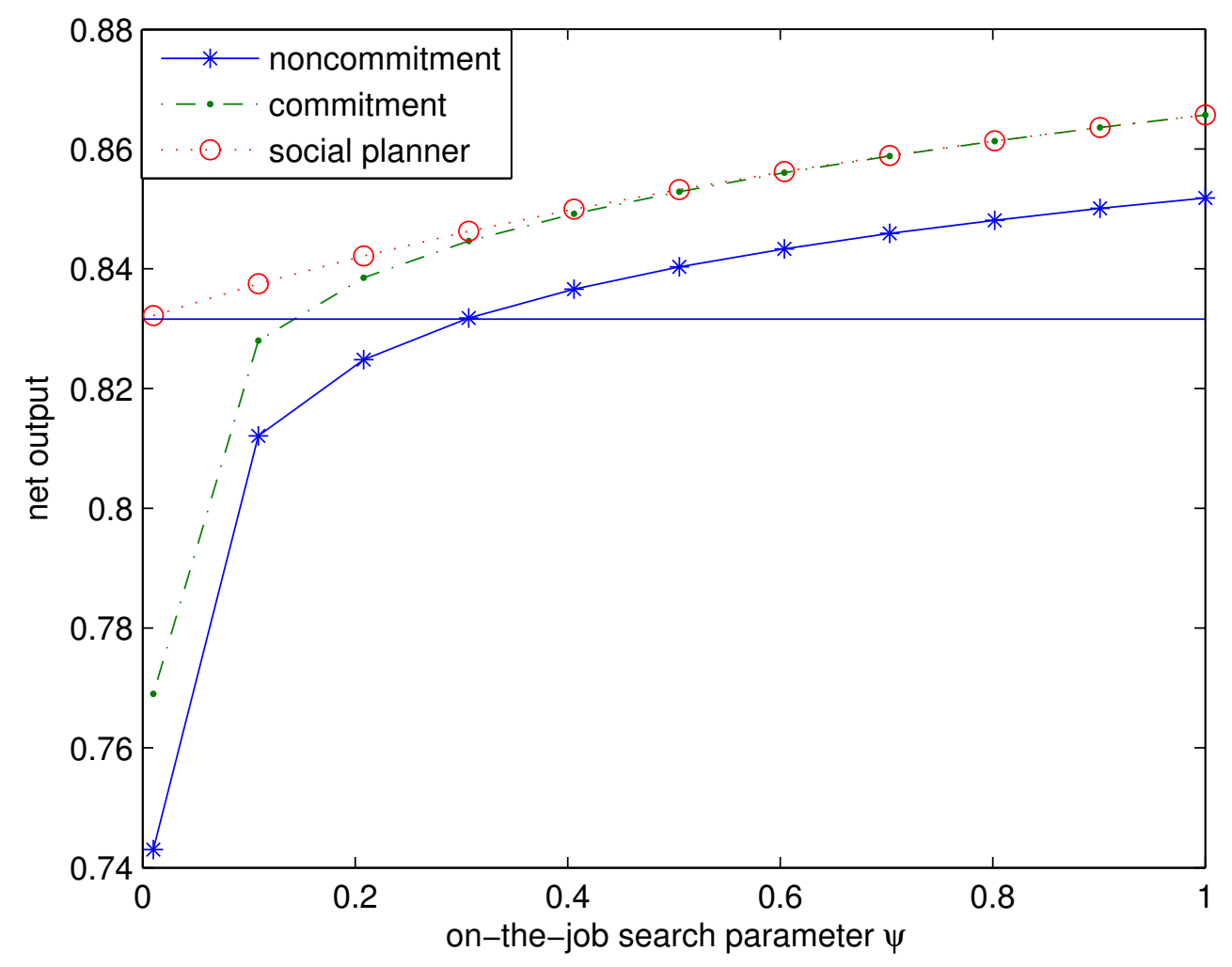

Figure 1: Model Comparison

decentralized bargaining. For higher values of $\psi, \mathrm{CBA}$ is not desirable. The reason is that it eliminates the incentive for on-the-job search which is crucial for social efficiency. When $\psi$ is small, the benefits of on-the-job search are also small. Firms can signal which workers they prefer but they meet few workers anyway. Therefore the benefits of CBA can in that case exceed the cost.

In the above analysis, we have imposed that the bargaining power parameter is 0 . Next we will relax the value of $\beta$ and check the robustness of results with respect to $\beta$.

Since the empirical magnitude of $\beta$ is unclear, in Figure 2 we present four cases: $\beta=0.0,0.1,0.4$ and 0.7. Starting at $\beta=0$, increasing $\beta$, reduces the business stealing externality. For $\beta=0.4$, we see that even for $\psi<0.1$, decentralized wage setting performs better than CBA. As we increase $\beta$ further, workers get inefficiently high bargaining power 


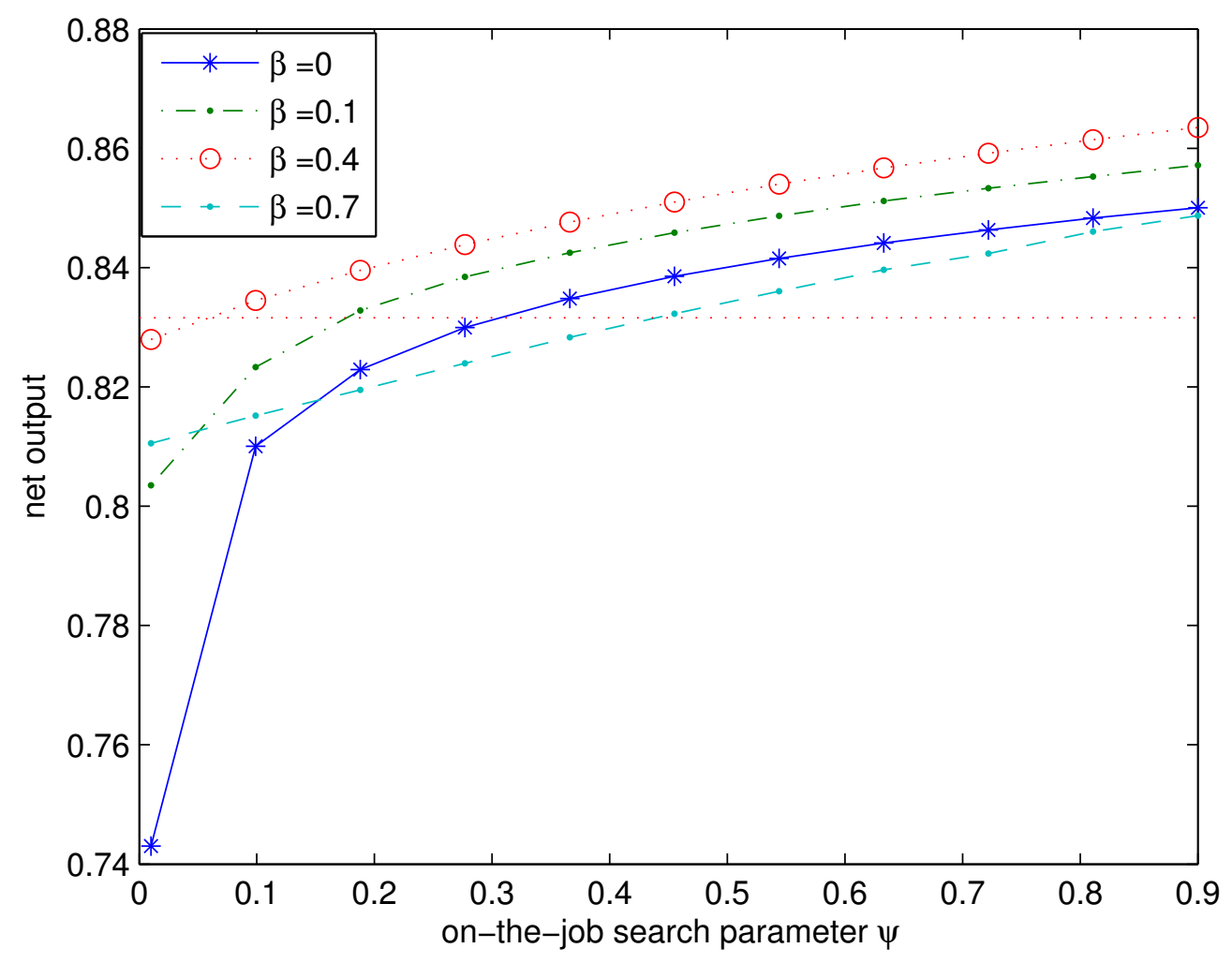

Figure 2: Model Robustness with respect to $\beta$

(for similar reasons as in Hosios, 1990) and we see that decentralized wage setting performs less good (the threshold $\psi$ above which decentralized bargaining performs better is now 0.45). The high bargaining power of workers leads to too little vacancy creation and too high unemployment. Empirically, Gautier and Teulings (2012) show that observed wage dispersion in the US can be well explained with $\beta=0$ so we do not view this as a realistic case.

\subsection{How large is $\psi$ ?}

Above, we saw that if we take the model serious, it is an empirical question whether CBA is desirable and this mainly depends on $\psi$. Below, we show that for both the Netherlands and the US, $\psi$ is above the threshold, implying that CBA reduces welfare. 
Nagypal (2005) and Gautier and Teulings (2011) derive how $\psi$ can be estimated from observed labor market flows. Let $f_{u e}$ be the unemployment-to-employment flow and $f_{e e}$ be the employment-to-employment flow. Then,

$$
\begin{aligned}
u f_{u e} & =2 \lambda(1-u), \\
(1-u) f_{e e} & =2 \int_{0}^{\bar{x}} \psi \lambda(1-u) g(x) x d x=2 \lambda(1-u)\left(\frac{1+\psi \bar{x}}{\psi \bar{x}} \ln (\psi \bar{x}+1)-1\right), \\
\frac{f_{e e}}{f_{u e}} & =\frac{u}{1-u}\left(\frac{1+\psi \bar{x}}{\psi \bar{x}} \ln (\psi \bar{x}+1)-1\right)=\frac{1+\psi \bar{x}}{\psi \bar{x}^{2}} \ln (\psi \bar{x}+1)-\frac{1}{\bar{x}} .
\end{aligned}
$$

Gautier and Teulings (2012) argue that for the U.S., $\frac{f_{e e}}{f_{u e}}$ varies from 0.076 to 0.132 (depending on which data one uses and whether one targets the average or median worker) implying that $\psi \simeq 0.75$. From Gautier et al. (1999), for the Netherlands we have $p_{e u}=0.039$ and $p_{e e}=0.0592$, implying that the on-the-job search efficiency parameter for the Netherlands is 0.45 . Both are higher than the threshold, implying that the net benefits of collective wage bargaining are negative even if $\beta=0$ and firms cannot ex ante commit to wages contingent on $x$.

The above analysis considers the on-the-job search intensity for the whole economy. If the labor market is segmented, then we can apply the above analysis to the sub-markets. For example, we might expect that workers who are capable of complex jobs will search only within that job category. In Table 2, the whole labor is divided by two different criterions: education of workers and job complexities. The data is for the Netherlands and from Gautier et al. (1999). We can see that only for the complex job category, if $\beta<0.1$ and if there is no commitment, that decentralized wage bargaining CBA could perform slightly better but this is also the segment where in practice wages are not set collectively. For all other cells, decentralized wage setting performs better than CBA.

\section{Final remarks}

In this paper we used a search model with ex ante heterogeneity to derive a threshold on the relative efficiency of on-the-job search below which centralized bargaining agreements are desirable. The empirical estimates for both the Netherlands and the US in the relevant 
Table 2: On-the-job search parameter values for different categories

\begin{tabular}{l|l|l|l}
\hline \hline Category & $p_{e u}$ & $p_{e e}$ & $\psi$ \\
\hline simple job & 4.08 & 6.67 & 0.5087 \\
intermediate job & 3.70 & 5.95 & 0.5237 \\
complex job & 4.41 & 4.92 & 0.2473 \\
\hline worker: low education & 4.20 & 5.96 & 0.3835 \\
worker: intermediate education & 3.54 & 5.37 & 0.4798 \\
worker: higher education & 3.51 & 5.75 & 0.5591 \\
\hline
\end{tabular}

segments are above this threshold (even if the bargaining power is 0) implying that the cost of CBA (the economy moves slower to the optimal allocation because wages loose their signaling function) exceed the potential benefits (the business-stealing externality can be internalized). If wages are inefficiently low, other instruments that do not reduce mobility (like a minimum wage) are preferable over CBA.

\section{References}

Bauer, C. And J. Lingens (2011). Does Collective Wage Bargaining Restore Efficiency in a Search Model with Large Firms? Mimeo University of Munich.

Burdett, K. And D. Mortensen (1998), Equilibrium wage differentials and employer size, International Economic Review, 39, 257-274.

Coles, M. (2001), Equilibrium Wage Dispersion, Firm Size, and Growth, Review of Economic Dynamics, 4-1,159-187.

Coles, M And D.T. Mortensen, (2011), Equilibrium Wage and Employment Dynamics in a Model of Wage Posting without Commitment, NBER Working Papers 17284, National Bureau of Economic Research

Delacroix, A. (2006), A multisectorial matching model of unions, Journal of Monetary Economics, 53, 573-596. 
Diamond, P.A. (1982), Aggregate demand management in search equilibrium, Journal of Political Economy, 90, 881-894.

Gautier, P.A., G.J. Van den Berg, J.C. Van Ours and G. Ridder (1999), Separations at the firm level, in: J. Haltiwanger, J. Lane, K. Troske and J. Theeuwes ed. The Creation and Analysis of Matched Employer-Employee Data, 1999, North Holland.

Gautier, P.A And C.N. Teulings (2011), Sorting and the Output Loss Due to Search Frictions, Mimeo Tinbergen Institute,

Gautier, P.A, C.N. Teulings And A.P. Van Vuuren (2010), On-the-Job Search, Mismatch and Efficiency, Review of Economic Studies, 77: 245-272.

Hosios, A.J. (1990), On the Efficiency of Matching and Related Models of Search and Unemployment, Review of Economic Studies, 57, 279-98.

Krusell P. And L. Rudanko (2012), Unions in a Frictional Labor Market, NBER working paper 18218.

Marimon, R. And F. Zilibotti (1999), Unemployment vs. mismatch of talents: reconsidering unemployment benefits, Economic Journal, 109, 266-291.

Mortensen, D.T. (1982), The matching process as a noncooperative bargaining game, in J.J. McCall, eds., The economics of information and uncertainty, Chicago: NBER, University of Chicago Press.

NAGyPAL, E. (2005), On the extent of job-to-job transitions, working paper, Northwestern University, Evanston.

Pissarides, C.A. (1986), Trade Unions and the Efficiency of the Natural Rate of Unemployment, Journal of Labor Economics ,4, 582-595.

Pissarides, C.A. (2000), Equilibrium unemployment theory, 2nd edition, MIT Press, Cambridge. 
Shimer, R. (2005), The cyclical behavior of equilibrium unemployment and vacancies, American Economic Review, 95, 25-49.

Shimer, R. (2006), On-the-job Search and Strategic Bargaining, in: H. Bunzel, B.J. Christensen, G.R. Neumann, and J.M. Robin, eds., Structural Models of Wage and Employment Dynamics, conference volume in honor of Dale Mortensen, Elsevier, Amsterdam.

Shimer, R. And L. Smith (2000), Assortative Matching and Search, Econometrica, 68, 343-369.

\section{Appendix}

\section{A Wages under no commitment for general $\beta$}

In this appendix we derive wages for general bargaining power and no commitment. The derivations for commitment are very similar. Let $\widehat{F}(W)$ be the survival function of the wage-offer distribution (which for well known reasons cannot have mass points, see Burdett and Mortensen, 1998). $W(x)$ maximizes the following product,

$$
W(x)=\arg \max _{W}\left[\hat{V}^{E}(W)-V^{U}\right]^{\beta}\left[\frac{Y(x)-W}{\rho+\delta+2 \psi \lambda v \bar{x} \widehat{F}(W)}\right]^{1-\beta} .
$$

Since $\hat{V}_{W}^{E}(W)=[\rho+\delta+2 \psi \lambda v \bar{x} \widehat{F}(W)]^{-1}$, we can write the first-order condition as,

$$
\begin{aligned}
\beta[Y(x)-W(x)] & =(1-\beta)\left[\hat{V}^{E}[W(x)]-V^{U}\right] \times \\
& {\left[\rho+\delta+2 \psi \lambda v \bar{x} \widehat{F}[W(x)]+2 \psi \lambda v \bar{x} \widehat{F}_{W}[W(x)][Y(x)-W(x)]\right], }
\end{aligned}
$$

Since $Y(x)$ is decreasing in the distance $x, W(x)$ is decreasing in $x$. Therefore,

$$
\begin{aligned}
V^{E}(x) & \equiv \hat{V}^{E}[W(x)], \\
2 v x & =\widehat{v}[W(x)] .
\end{aligned}
$$

The second line follows from the uniformity of unemployed workers and of vacancies. Using the chain rule gives,

$$
\begin{aligned}
V_{x}^{E}(x) & =\hat{V}_{W}^{E}[W(x)] W_{x}(x), \\
2 v & =\widehat{v}_{W}[W(x)] W_{x}(x) .
\end{aligned}
$$


Substitution of (19) and the expression for $Y(x)$ in the first order condition and rearranging terms yields

$$
W_{x}(x)=\frac{2(1-\beta) \psi \lambda v\left[1-\frac{1}{2} \gamma x^{2}-W(x)\right]\left[V^{E}(x)-V^{U}\right]}{\beta\left[1-\frac{1}{2} \gamma x^{2}-W(x)\right]-(1-\beta)\left[V(x)-V^{U}\right](\rho+\delta+2 \psi \lambda v x)} .
$$

We solve this differential equation numerically. 